\title{
Diagnosis of hyperferritinemia in 2019
}

\author{
Khalid Serraj ${ }^{1 *}$, Siham Hamaz ${ }^{1}$, Habiba Alaloui ${ }^{1}$, Houda Bachir ${ }^{1}$ and Emmanuel Andrès ${ }^{2}$ \\ ${ }^{1}$ Internal Medicine Department, University Hospital of Oujda, Morocco \\ ${ }^{2}$ Internal Medicine Department, University Hospitals of Strasbourg, France
}

\begin{abstract}
Although hyperferritinemia is not specific, it may be diagnostically very contributing if well interpreted by the physician. Physiologically, ferritin is a protein synthesized essentially by the liver and intended to store iron in the liver, macrophage and erythrocyte. Despite this, the increase in ferritinemia does not necessarily mean iron overload or liver disease. A global approach integrating the degree of ferritinemia, anamnesis and clinical context makes possible in the vast majority of cases to find the cause of hyperferritinemia without going through the saturation factor of transferrin and thorough liver investigations. The use of transferrin saturation coefficient, liver imaging, genetic tests or even liver biopsy proves to be necessary only in rare cases where the most obvious causes could not be identified.
\end{abstract}

\section{Introduction}

Unlike hypoferritinemia, which almost constantly reflects iron deficiency, hyperferritinemia is often difficult to interpret in the absence of an obvious clinical context. In medical practice, major hyperferritinemia greater than $1000 \mu \mathrm{g} / \mathrm{l}$ is a classic situation. Moore et al. had published in 2013 the results of a 2-year study in a department of internal medicine that found a major hyperferritinemia in 627 patients with the most common causes of cancer [1]. Vardi et al. found similar results with a pejorative prognostic value of severe hyperferritinemia, regardless underlying cause [2]. Another much older study by Lee et al. found similar frequencies of hyperritinemia in the previous two studies with high frequency of etiological associations in the same patients [3]. The high frequency of hyperferritinemia, their wide etiological spectrum and the frequent concomitant presence of several etiologies reflect the need to address hyperferritinemia based on a global vision prioritizing the most obvious and serious causes.

\section{Iron metabolism and some definitions according gen- der}

Hyperferritinemia is defined by serum values $>400 \mu \mathrm{g} / \mathrm{l}$ in men and $>300 \mu \mathrm{g} / \mathrm{l}$ in women. According to NHANES III, values generally found in the general population rarely exceed $200 \mu \mathrm{g} / \mathrm{l}$ in men and $150 \mu \mathrm{g} / \mathrm{l}$ in women. Furthermore, in a study by Murtagh et al. on patients with confirmed hereditary haemochromatosis, ferritin levels were between 300 and $3000 \mu \mathrm{g} / \mathrm{l}$ for men and between 250 and $3000 \mu \mathrm{g} / \mathrm{l}$ for women. The interpretation of the limit values for ferritinemia must therefore be extremely cautious, especially in the absence of a plausible condition explaining these values. A ferritinemia between 300 and $400 \mu \mathrm{g} / \mathrm{l}$ in men and between 200 and $300 \mu \mathrm{g} / \mathrm{l}$ in women can be synonymous with a real overload martial imposing a close biological monitoring or a thorough assessment from the outset. On the other hand, a ferritinemia less than $100 \mu \mathrm{g} / \mathrm{l}$ in an inflammatory context or any other hyperferritinemic situation should be considered a potential iron deficiency and managed as such $[4,5]$.

A small amount of exogenous iron not exceeding $2 \mathrm{mg} /$ day is absorbed by the duodenum and partially stored in the enterocytes as ferritin. Most of the body's iron comes from a recycling phenomenon through macrophages that provide physiological hemolysis and degradation of senescent hemoglobin. This iron is subsequently transported to the bone marrow at a rate of $20 \mathrm{mg}$ per day but also and especially to the hepatocytes which are the main storage site for ferritin. Excretion is through enterocytes and menstruation. Ferritin is a protein synthesized by the liver in the form of an egg about $12 \mathrm{~nm}$ in diameter able to store up to 5000 iron atoms. It is present mainly in hepatocytes, macrophages and cells of the red line but remains extremely ubiquitous topographically and functionally, which explains its elevation in several etiologies including hepatopathies, inflammation and cytolysis in addition to overload martial [6].

\section{Main causes of hyperferritinemia}

\section{Hereditary hemochromatosis}

The absorption of dietary iron is done by the enterocyte through the carriers "DMT1" and "Ferroportin". Subsequently, passage through the circulation, transferrin binding and interaction with the transferrin receptor (TFR) of the cryptic cell and the hepatic HFE protein occur. Ferroportin is also present on the surface of the macrophage. In the healthy person, there is a sufficient production of hepcidin which has as a function the negative regulation of the activity of DMT1 and ferroportin and therefore the limitation of the passage of iron in the blood from the enterocyte and macrophage. In the person with HFE mutation, there are 3 essential abnormalities: 1) Alteration of the HFE-TFR interaction resulting in less iron entry into the cryptic cell and the emission of a false deficiency signal resulting in an absorptive response of iron; 2) A release of enterocyte iron to the plasma by hyperactivity DMT1 and ferroportin; 3) A release of macrophagic iron by hyperactivity of macrophagic ferroportin. The consequence of these

${ }^{\star}$ Correspondence to: Khalid Serraj, Internal Medicine Department, University Hospital of Oujda, Morocco, E-mail: serrajkhalid@yahoo.fr

Key words: ferritin, hemochromatosis, inflammation, cytolysis, metabolic syndrome, alcohol

Received: December 21, 2018; Accepted: January 14, 2019; Published: January 17, 2019 
abnormalities is an increase initially in the transferrin saturation coefficient (TSC) and then in ferritin with an accumulation of tissue iron and the occurrence of organic damage, particularly liver, joint, glandular, cardiac and cutaneous explaining the characteristic triad "cirrhosis-diabetes-melanoderma". The first manifestations of the disease occur in adulthood with later onset in women because of the protective role played by menstruation. In practice, the diagnosis is based on the elevation of the TSC, the elimination of other obvious causes of this elevation such as cytolysis and hepatopathy and the demonstration of a homozygous mutation HFE C282Y or composite C282Y/H63D. The search for other mutations on the genes of the HFE or TFR receptors will be considered in rare cases where the table is typical and very evocative with negativity of the usual mutations. Hepatic biopsy has been less and less necessary since the advent of genetic tests, as well as liver MRI, which is very efficient in assessing hepatic parenchymal iron overload [7].

\section{Metabolic syndrome}

Abdominal obesity, arterial hypertension, glycemic and lipid disorders and microalbuminuria are the criteria taken into account by WHO to define the metabolic syndrome whose main pathophysiological axis is insulin resistance. The very high prevalence of hyperferritinemia in patients with metabolic syndrome is currently established. The COLAUS study published in 2008 focused on 3063 women and 2752 men and had clearly demonstrated this finding $(2.2 \%$ vs. $11.4 \%$ for women and $25 \%$ vs. $40.6 \%$ for men). This close epidemiological association is supported by the study of Brudevold et al., which showed a proportional increase in serum ferritin levels as a function of the level of peptide C, apart from any other cause of iron overload [8]. One of the main conditions associated with the metabolic syndrome is steatosis and non-alcoholic steatohepatitis where it is currently demonstrated the presence of several hepatocyte disorders related to insulin resistance with a cellular uptake of iron clearly superior to the externalization. The occurrence of hepatic inflammation in the context of steatohepatitis gives rise to cytolysis and may in this way aggravate hyperferritinemia. The predominance of tissue and cell abnormalities explains why the hyperferitinemia of the metabolic syndrome is only rarely accompanied by an increase in the CST, whereas hepatic MRI often reveals an obvious overload [9].

\section{Cytolysis}

The hyperferritinemia of cytolysis is explained by the ubiquitous presence of ferritin in hepatocytes, monocytes, erythrocytes and muscle cells, as well as pancreatic, testicular, bronchial, placental and renal cells. Hyperferrinemias of cytolysis are often multifactorial and should not be "easy" on cell lysis before ruling out other potential associated causes. In a study of Kotoh et al. performed on 100 patients with acute hepatitis, the ferritin level correlated closely with that of ALT but with a particularly severe elevation in the group of viral hepatitis thus implying a participation of anti-macrophage activation. Another study had shown elevated ferritin levels in patients with dermatomyositis but with a greater increase in the subgroup with more than one interstitial lung disease ( 790 vs $186 \mathrm{ng} / \mathrm{ml}, \mathrm{P}<0.0001$ ). Finally, hyperferritinemia of hemolytic anemia is more marked in thalassemia than in other causes of hemolysis because of the particularities of iron hyperabsorption and transfusion requirements in thalassemic individuals. TSC during cytolysis is classically elevated due to massive plasma release of intracellular iron, particularly hepatic and erythrocyte iron [10-12].

\section{Inflammation}

Increase of ferritinemia is related to both direct stimulation by prostaglandins and lipopolysaccharides and indirect through the increase of $\mathrm{NO}$ and oxidative stress induced by pro-inflammatory cytokines. In a recent study of Vanarsa et al. in lupus patients, it was clearly demonstrated in the active forms of lupus that ferritin was increased not only in the serum $(\mathrm{p}<0.001)$ but also in urinary sites, particularly in urine, in patients with nephropathy $(\mathrm{p}<0.0001)$. Inflammatory ferritinemia does not typically exceed $1000 \mathrm{ng} / \mathrm{ml}$ and is not accompanied by an elevation of the TSC. Two situations are important to differentiate: on the one hand hyperferritinemias higher than $1000 \mathrm{ng} / \mathrm{ml}$ which would orient more towards the Still's disease, the serious septic states and the hemophagocytosis syndromes and on the other hand the inflammations with "normal" ferritin which must lead to take out masked martial deficiency [13-16].

\section{Alcohol consumption}

The link between alcohol and hyperferritinemia has been known for a long time and is well understood physiopathologically. Alcohol leads to direct stimulation of ferritin synthesis regardless of its pathogenic effect on the liver. Significant alcohol consumption should be sought in any patient with hyperferritinemia. Alcohol withdrawal leads to a rapid decline in ASAT, GGT and ferritinemia within 15 days of cessation of alcohol consumption. This test is both diagnostic and therapeutic. The biological phenotype of alcoholic hyperferritinemia is a classic absence of increased TSC with inconsistent hepatic iron overload on MRI, whether or not there is already established alcoholic liver disease [17].

\section{Still's disease, Anti-phospholipids and Haemophagocytic syndrome}

A major hyperferritinemia greater than 1000 is usually directed to particular etiologies like still disease, macrophage activation syndrome and catastrophic syndrome of antiphospholipid antibodies (CAPS). In Still's disease, functional prognosis is related to joint damage and life-threatening hepatic involvement, DIC, SAM, myocardial involvement and amyloidosis. The absence of major hyperferritinemia in Still's disease simply requires rethinking the diagnosis. The TSC has no value because the clinic is immediately very evocative. On the other hand, glycosylated ferritin less than $20 \%$ is a relevant and highly characteristic element that is one of the major diagnostic criteria for the disease (Table 1) [18].

In the macrophage activation syndrome, there is a real cytokine storm linked to an initial overactivation of T lymphocytes of genetic, infectious, tumoral or autoimmune origin, an activation in the second time of macrophages under the effect of interferon, TNF alpha, interleukin- 6 and M-CSF and finally increased phagocytosis by activated macrophages of mature cells including figured elements of the blood. This macrophage activation in turn results in a positive feedback on $\mathrm{T}$ lymphocytes and a loop co-stimulation process that maintains the inflammatory and phagocytic phenomena. In the same way as in still disease, the clinical picture here is very obvious and diagnosis can be made without TSC. In practice, the clinical picture is that of a febrile tumor syndrome with pancytopenia, hypertryglyceridemia, elevation of LDH and signs of haemophagocytosis in the medullary study or lymph node biopsy (Table 1). With a mortality approaching $60 \%$, the simple suspicion of a SAM should lead to an immediate and the widest possible treatment targeting the most common causes namely bacterial, fungal, herpetic and tuberculous infections as well as malignancy including lymphomas [19]. 
Table 1. Diagnostic criteria of still disease, CAPS and hemophagocytosis syndrome

\begin{tabular}{|c|c|c|}
\hline $\begin{array}{l}\text { Still disease } \\
\text { (Fautrel 2002) }\end{array}$ & Catastrophic anti-phospholipids Syndrome (2010) & $\begin{array}{l}\text { Haemophagocytic syndrome } \\
\text { (Imashuku 1997) }\end{array}$ \\
\hline $\begin{array}{l}\text { Major criteria } \\
\text { Fever } \\
\text { Joint pain } \\
\text { Intermittent erythema } \\
\text { Pharyngitis } \\
\text { Neutrophilia } \geq 80 \% \\
\text { Glycated ferritin } \leq 20 \% \\
\text { Minor criteria } \\
\text { Maculopapular rash } \\
\text { Leucocytosis } \geq 10000 / \mathrm{mm}^{3} \\
4 \text { major criteria or } 3 \text { major }+2 \text { minor criteria }\end{array}$ & $\begin{array}{l}3 \text { organs damage } \\
\text { Simultaneous occurrence in less than a week } \\
\text { Histological microvascular occlusion } \\
\text { Presence of antiphospholipid antibodies } \\
\text { Diagnosis if presence of the } 4 \text { criteria }\end{array}$ & $\begin{array}{l}\text { Fever }>38,5 \text { ou }>7 \text { days } \\
\text { Cytopenia } \geq 2 \\
\text { Ferritin } \geq 1000 \\
\text { LDH } \geq 1000 \\
\text { Bone marrow, splenic, hepatic or lymphoid } \\
\text { haemophagocytosis, } \\
\text { Main causes: CMV, VIH, HSV, EBV, Mycobacteria, } \\
\text { Lymphoma, Solid malignancy }\end{array}$ \\
\hline
\end{tabular}

Table 2. Paraclinical characteristics of hyperferritinemia according etiology

\begin{tabular}{|c|c|c|c|}
\hline Ferritin & Plasmatic & Tissue \\
iron
\end{tabular}

Finally, the CAPS carry out a thrombotic microangiopathy table which clinically results in a multi-organ failure related to a generalized activation of the micro and macrovascular thrombotic cascade [20]. Mortality is also very important even with a rapid and complete therapeutic intervention.

Table 2 summarize in a simplified and didactic way the main pathophysiological mechanisms of hyperferritinemias according to the etiologies as well as their implications on the paraclinical profile of patients.

\section{Conclusion}

It is necessary to separate the etiologies of hyperferritinemia into 3 main essential categories:

- Causes that are quickly detectable by interrogation, clinic and simple paraclinical examinations and whose management is often easy and allows a fairly rapid reversibility by simple measures of eviction and etiological treatment.

- Causes whose clinical presentation is very telling and quickly leads to a rather narrow and specific etiological spectrum. These are most often serious causes that must be sought first.

- Chronic causes often paucisymptomatic at the beginning and can evolve long low noise making it then indispensable the use of other parameters such as CST, hepatic MRI and the search for mutations of hereditary hemochromatosis or even other examinations Molecular and cytogenetic more advanced.

\section{References}

1. Moore C, Ormseth M, Fuchs H (2013) Causes and significance of markedly elevated serum ferritin levels in an academic medical center. J Clin Rheumatol 19: 324-328. [Crossref]

2. Vardi M, Hogerat T, Cohen S, Cohen S (2014) Significance of extremely elevated ferritin level in medical inpatients. Cent Eur J Med 9: 115-120.
3. Lee MH, Means RT (1995) Extremely elevated serum ferritin levels in a university hospital: associated diseases and clinical significance. Am J Med 98: 566-571. [Crossref]

4. Edwards CQ, Kushner JP (1993) Screening for hemochromatosis. N Engl J Med 328 1616-1620. [Crossref]

5. Zacharski LR, Ornstein DL, Woloshin S, Schwartz LM (2000) Association of age, sex, and race with body iron stores in adults: analysis of NHANES III data. Am Heart $J 140$ 98-104. [Crossref]

6. Saito H (2014) Metabolism of iron stores. Nagoya J Med Sci 76: 235-254. [Crossref]

7. Pietrangelo A (2004) Hereditary hemochromatosis--a new look at an old disease. $N$ Engl J Med 350: 2383-2397. [Crossref]

8. Waeber G, Vollenweider P, Marques P, Vidal M (2013) Hyperferritinémie associée au syndrome métabolique: une nouvelle cible thérapeutique? Rev Med Suisse 9: 20022007.

9. Sumida Y, Yoshikawa T, Okanoue T (2009) Role of hepatic iron in non-alcoholic steatohepatitis. Hepatol Res 39: 213-222. [Crossref]

10. Kotoh K, Ueda A, Tanaka M, Miyazaki M, Kato M, et al. (2009) A high prevalence of extreme hyperferritinemia in acute hepatitis patients. Hepat Med 1: 1-8. [Crossref]

11. Gono T, Kawaguchi Y, Hara M, Masuda I, Katsumata Y, et al. (2010) Increased ferritin predicts development and severity of acute interstitial lung disease as a complication of dermatomyositis. Rheumatology 49: 1354-1356. [Crossref]

12. Chattopadhyay K, Biswas R, Bhattacherjee S, Bandyopadhyay R (2012) An epidemiological study on the clinic-hematological profile of patients with congenital hemolytic anemia in a tertiary care hospital of Kolkata. Indian J Prev Soc Med 43: 372-377.

13. Rosário C, Zandman-Goddard G, Meyron-Holtz EG, CruZ D, Shoenfeld Y (2013) The Hyperferritinemic Syndrome: macrophage activation syndrome, Still's disease, septic shock and catastrophic antiphospholipid syndrome. BMC Med 11: 185. [Crossref]

14. Ruscitti P, Giacomelli R (2018) Pathogenesis of adult onset still disease: curren understanding and new insights. Expert Rev Clin Immunol 14: 965-976. [Crossref]

15. Vanarsa K, Ye Y, Han J, Xie C, Mohan C, et al. (2012) Inflammation associated anemia and ferritin as disease markers in SLE. Arthritis Res Ther 14: R182. [Crossref]

16. Kernan KF, Carcillo JA (2017) Hyperferritinemia and inflammation. Int Immunol 29: 401-409. [Crossref] 
17. Meyer TE, Kassianides C, Bothwell TH, Green A (1984) Effects of heavy alcohol consumption on serum ferritin concentrations. S Afr Med J 66: 573-575. [Crossref]

18. Mehta B, Efthimiou P (2012) Ferritin in adult-onset still's disease: just a useful innocent bystander? Int J Inflam 2012: 298405. [Crossref]
19. Szyper-Kravitz M (IMAJ) The hemophagocytic syndrome/macrophage activation syndrome: A final common pathway of a cytokine storm. Isr Med Assoc J 11: 633-634. [Crossref]

20. Aguiar CL, Erkan D (2013) Catastrophic antiphospholipid syndrome: How to diagnose a rare but highly fatal disease. Ther Adv Musculoskelet Dis 5: 305-314. [Crossref]

Copyright: (C2019 Serraj K. This is an open-access article distributed under the terms of the Creative Commons Attribution License, which permits unrestricted use, distribution, and reproduction in any medium, provided the original author and source are credited. 